\title{
UTILIZAÇÃO DE CONTRATOS FUTUROS AGROPECUÁRIOS NO PERFIL MÉDIO DE INVESTIMENTOS DOS FUNDOS DE PENSÃO NO BRASIL ${ }^{1}$
}

\author{
USE OF AGRICULTURAL FUTURE CONTRACT IN THE MEAN \\ INVESTMENT PROFILE OF PENSION FUNDS IN BRAZIL
}

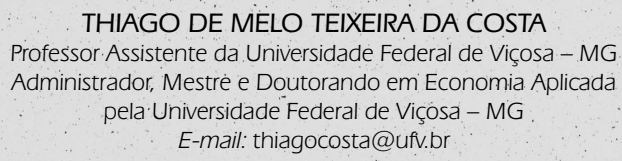

THIAGO DE MELO TEIXEIRA DA COSTA

Professor Assistente da Universidade Federal de Viçosa - MG

Administrador, Mestre e Doutorando em Economia Aplicada pela Universidade Federal de Viçosa - MG

E-mail: thiagocosta@ufv.br

\author{
CARLOS ALBERTO PIACENTI \\ Professor Assistente da Uñiversidade Estadual do Oeste do Paraná - PR, \\ Pesquisador do grupo de Pesquisa em Agronegócio e \\ Desenvolvimento Regional (GEPEC) \\ Economista, Mestre em Economịa Rural pela Universidade \\ Federal de Viçosa - MG e Doutorando em Economia Aplicada \\ pela Universidade Federal de Viçosa - MG \\ E-mail: piacenti8@yahoo.com.br
}

\section{RESUMO}

Os Fundos de Pensão têm se tornado cada vez mais representativos no cenário mundial. A sustentabilidade dessas instituições exige um eficiente processo de gerenciamęnto de suas carteiras de investimento. Ao mesmo tempo, as negociações com contratos futuros agropécuários vêm se consolidando no Brasil e surgem como uma alternativa para investidores que queiram diversificar suas carteiras. $\mathrm{O}$ objetivo deste trabalho foi avaliar a viabilidade da utilização de derivativos agropecuários como forma de minimização de riscos em carteiras de investimentos de Fundos de Pensão no Brasil, dentro dos limites legais aos quais essas entidades estão sujeitas, tomando como referência o perfil médio dessas instituições no país com relação à aloçação de seus investimentos. Para isso, avaliou-se o desempenho de carteiras sem e com $1 \%$ de seus investimentos em derivativos agropecuários. As análises de risco foram feitas através do modelo Value-at-risk (VaR), utilizando modelos de variância condicional para a extração da série diária de volatilidades. Os retornos foram ponderados pelo risco, através do Índice de Sharpe Adaptado (ISA). Os resultados mostraram que, dentro dos parâmetros estabelecidos para cada modalidade de investimento, a introdução de contratos futuros agropecuários foi benéfica, reduzindo o risco mais que proporcionalmiente ao retorno. O trabalho torna-se mais significativo à medida que se analisam os montantes financeiros envolvidos. Considerando, por exemplo, que os Fundos de Pensão invistam, de forma geral, $1 \%$ de seus ativos, seriam injetados, no mercado futuro de commodities agropecuárias, mais de R $\$ 2$ bilhões, valor que representa, dentro da movimentação financeira de 2004, aproximadamente $10 \%$ de todos os recursos investidos.

Palavras-chave: Fundos de Pensão. Derivativos Agropecuários. Value-at-risk. ISA.

\section{ABSTRACT}

Pension Funds have become increasingly representative internationally and nationally. These institutions present an efficient administration of their investment portfolios. At the same time, the negotiations with agricultural future contracts are increasingly consolidated in Brazil as an alternative for investors wanting to diversify their portfolios. This work aimed to evaluate the viability of using agricultural derivatives as a form of minimizing the risks of investment portfolios of Pension Funds in Brazil, within the legal limits those entities are submitted to, based on these institutions' profile in relation to the allocation of their investments in the country. Thus, the performance of portfolios without and with $1 \%$ agricultural derivatives was assessed. The risk analyses were accomplished through the model Value-atrisk (VaR), using conditional variance models (Family GARCH) for the extraction of the daily series of volatilities. The returns were risk - weighted by the Adapted Sharpe Index.(ASI). The results showed that, within the established parameters for each investment modality, the introduction of agricultural future contracts was beneficial for all the proposed profiles, reducing the risk more than proportionally to the return. The work becomes more significant as the financial figures involved are analyzed. Assuming, for instance, that the Pension Funds invest, overall, $1 \%$ of their assets, it is expected that over $R \$ 2$ billion would be injected into the future market of agricultural commodities, a value representing approximately $10 \%$ of all invested resources in financial movements for 2004.

Keywords: Pension Funds. Agricultural derivatives. Value-at-Risk. Adapted Sharpe Index.

Recebido em 26.04.2007 • Aceito em 11.09.2007 • 2a versã̃o aceita em 24.08.2007

1 O Artigo é um desdobramento da Dissertação de Mestrado em Economia Aplicada da Universidade Federal de Viçosa, intitulada: Viabilidade da Utilização de Derivativos Agropecuários em Carteiras de Investimentos de Fundos de Pensão no Brasil, realizado pelo primeiro autor, sob orientação do Prof. Carlos Antônio Moreira Leite, publicada em 2005 e financiada pela CAPES. 


\section{INTRODUÇÃO}

Os Fundos de Pensão têm se tornado cada vez mais representativos na atual conjuntura brasileira, tanto como fonte de benefício para seus participantes como para a economia, por serem importantes canalizadores da poupança para investimentos e segurança dos aposentados na manutenção do bem-estar futuro. O crescimento do patrimônio administrado por esses fundos, atingiu em julho de 2004, o valor de $R \$ 256$ bilhões no Brasil, segundo a Associação Brasileira das Entidades Fechadas de Previdência Privada - ABRAPP (2004a).

Nesse sentido, surge a necessidade de mecanismos que auxiliem na condução da política de investimentos dessas instituições, para que, cada vez mais, seu papel possa ser cumprido de forma satisfatória. O processo de gerenciamento das carteiras de investimento dos Fundos de Pensão é parte fundamental da busca pela eficácia organizacional.

Segundo Paula (2001), o gerenciamento do risco de mercado mostra-se como uma ação de extrema relevância na gestão dos recursos das entidades de previdência privada. Para Pereira Filho (2002), a exigência de gestão qualificada dos Fundos de Pensão é ampliada pela importância vital que os recursos representam para seus participantes, que, por longo tempo, anseiam pelo recebimento de suas rendas de aposentadoria. Para atender a esses objetivos, os Fundos de Pensão devem almejar a eficiência de seus investimentos, diminuindo riscos e buscando os maiores retornos de suas carteiras; ao mesmo tempo, necessitam se adequar às normas vigentes em seus estatutos e na legislação, que estabelecem, entre outras coisas, limites para alocação de recursos nas diversas modalidades de investimento (Renda Fixa, Renda Variável, Imóveis etc.).

De acordo com a Teoria do Portfolio de Markowitz (1952), a composição de carteiras de investimentos, combinando ativos que apresentam correlação inferior a um entre seus retornos individuais, torna possível reduzir o risco sem prejudicar o retorno esperado da mesma. Segundo Mattos (2000), ações e derivativos agropecuários possuem essa propriedade. Greer, citado por Silva (1998), afirma que, historicamente, os benefícios em investir em commodities para uma carteira têm mostrado redução da volatilidade e, muitas vezes, aumento do retorno ao mesmo tempo.

Segundo Pereira Filho (2002), os derivativos mostramse como forte instrumento na gestão integrada de riscos; o seu uso para a proteção de carteiras de ações pode apresentar vantagem comparativa na avaliação de desempenho, proporcionando maior estabilidade ao retorno esperado para o plano, ao mesmo tempo em que reduz o risco proveniente do mercado acionário.

Em especial, vale ressaltar o desenvolvimento de derivativos agropecuários no Brasil, que conta com diversas commodities negociadas na Bolsa de Mercadorias e Futuros (BMEF).

De acordo com Fontes et al. (2004), o aumento do conhecimento e, conseqüentemente, do interesse dos investidores no mercado derivativo agropecuário vai ocasionar uma melhor aceitação e distribuição dos riscos, criando um ambiente mais confiável de investimento, gerando todo um processo positivo de incremento de negociações e atraindo, assim, novos agentes para esse mercado.

Considerando que, em geral, a utilização desse instrumento de diversificação com futuros agropecuários não é comum nas instituições de Previdência Privada brasileiras e que o contrário poderia gerar benefícios tanto para essas instituições como para o processo de comercialização por meio da BMEF, torna-se evidente a importância de estudos que busquem avaliar se a introdução de derivativos agropecuários em carteiras de investimentos dos Fundos de Pensão brasileiros gera efeitos positivos no que se refere à minimização dos riscos provenientes do mercado financeiro e à satisfação, concomitantemente, das expectativas de retorno planejadas por esses fundos, meta atuarial, e das normas, para alocação dos recursos, impostas pela legislação.

Dessa forma, novas contribuições podem ser dadas à literatura já existente na área, tanto no que se refere à especificidade dos Fundos de Pensão, que geram um caráter singular na composição de suas carteiras, como no aspecto metodológico, que visa a unir instrumentos modernos de cálculo de risco ao processo de diversificação das carteiras sugerido no estudo.

\subsection{Objetivos}

O principal objetivo consiste em avaliar a viabilidade da utilização de derivativos agropecuários como forma de minimização de riscos em carteiras de investimentos de Fundos de Pensão no Brasil, tomando como referência o perfil médio dessas instituições no país com relação à alocação de seus investimentos. Especificamente pretende-se:

- Verificar os níveis de correlação entre os derivativos agropecuários e os demais ativos que fazem parte das carteiras dos Fundos de Pensão no Brasil.

- Analisar o nível de risco das carteiras de investimento que combinem derivativos agropecuários e outros ativos utilizados em portfolios de Fundos de Pensão no Brasil através do Valor em Risco (VaR).

- Verificar se a diversificação, levando em conta os derivativos agropecuários, eleva as relações de retorno/risco esperados para este estudo, de acordo a Teoria do Portfolio de Markowitz. 


\section{FUNDOS DE PENSÃO NO BRASIL}

A história oficial dos Fundos de Pensão e da Previdência Complementar no país começa no ano de 1977, com a aprovação da Lei $n^{\circ} 6.435$, do dia 15 de julho, que regula a criação de entidades que ofereçam complemento à aposentadoria oficial.

As Entidades Fechadas de Previdência Privada vêm recebendo grande impulso desde a sua criação; com a nova regulamentação vigente, ou seja, o lançamento da figura do instituidor, a regulamentação dos fundos multipatrocinados, entre outras, esse efeito deve aumentar. A evolução do número de Fundos de Pensão autorizados a funcionar no período de 1980 a 2002 no Brasil passou de menos de 100 para mais de 350 em pouco mais de 20 anos.

Desses Fundos de Pensão autorizados, a maior parte, hoje, é patrocinada por empresas privadas nacionais, superando o setor púbico. Apesar disso, a maior parte do patrimônio desses fundos está ainda relacionada a empresas públicas, cabendo a PREVI, PETROS e FUNCEF as primeiras colocações no ranking dos maiores investimentos.
Na Tabela $1 \boldsymbol{0}$, tem-se a relação dos 10 maiores Fundos de Pensão do Brasil no ano de 2005, por investimento, além de relacionar o número de participantes e de dependentes. Dentre eles, a PREVI se sobressai com quase o triplo de investimento do segundo colocado que é a PETROS.

Conforme dados da Tabela 2 0, o patrimônio dos Fundos de Pensão vem crescendo de forma sistemática desde 1994 , ultrapassando no final de 2005 a casa dos R $\$ 320$ bilhões. Apesar de representar um volume expressivo de recursos, esse valor ainda é incipiente quando comparado ao de outros países, como os EUA, por exemplo, onde o patrimônio das Entidades Fechadas de Previdência Complementar atingiu, até 2002, aproximadamente US\$ 7 trilhões.

As Entidades Fechadas de Previdência Privada (EFPP), ou simplesmente Fundos de Pensão, de acordo com Baima (1998), são entidades de direito privado, sem fins lucrativos, constituídas facultativamente pelas organizações e seus funcionários, com o objetivo de assegurar aos seus participantes e beneficiários proteção nas dificuldades so-

Tabela 1 Ranking dos investimentos dos 10 maiores Fundo de Pensão no Brasil em 2005

\begin{tabular}{c|l|c|c|c|c} 
Posição & Fundos de Pensão & Investimentos & Participantes & Dependentes & Assistidos \\
\hline 1 & PREVI & 82.947 & 83.291 & 247.674 & 77.796 \\
\hline 2 & PETROS & 28.607 & 40.383 & 167.839 & 52.675 \\
\hline 3 & FUNCEF & 21.154 & 52.050 & 174.579 & 22.962 \\
\hline 4 & FUNDAÇÃO CESP & 10.667 & 19.014 & 79.695 & 28.647 \\
\hline 5 & SISTEL & 7.498 & 6.813 & 62.228 & 27.141 \\
\hline 6 & VALIA & 7.162 & 33.873 & 125.053 & 20.071 \\
\hline 7 & CENTRUS & 6.810 & 100 & 1.792 & 1.723 \\
\hline 8 & ITAUBANCO & 6.741 & 31.350 & 6.735 & 6.986 \\
\hline 9 & FORLUZ & 4.912 & 10.456 & 43.622 & 11.617 \\
\hline 10 & REAL GRANDEZA & 3.892 & 4.353 & 22.485 & 7.107
\end{tabular}

Fonte: ABRAPP, 2006

Tabela 2 | Evolução dos Ativos dos Fundos de Pensão no Brasil no período de 1994 a 2005

\begin{tabular}{c|c} 
Ano & Ativos (R\$ milhões) \\
1994 & 72.742 \\
\hline 1995 & 74.815 \\
\hline 1996 & 86.629 \\
\hline 1997 & 101.033 \\
\hline 1998 & 101.129 \\
\hline 1999 & 125.995 \\
\hline 2000 & 144.025 \\
\hline 2001 & 171.152 \\
\hline 2002 & 189.280 \\
\hline 2003 & 240.139 \\
\hline 2004 & 280.517 \\
\hline dez/05 & 320.200
\end{tabular}

Fonte: ABRAPP, 2006 
ciais e na velhice, por meio de benefícios que são custeados pela patrocinadora - no caso, a própria organização - e pelos seus participantes, os seus funcionários. Em decorrência do acúmulo de capital, os Fundos de Pensão funcionam também como importantes investidores nos mais diversos ramos da economia, sendo, assim, importantes agentes para o desenvolvimento econômico do país.

O que vem ocorrendo com freqüência é a união de várias organizações para a criação de seus fundos de pensão. Esses são os Fundos Multipatrocinados, ou seja, apenas uma entidade fechada de previdência complementar é financiada por duas ou mais empresas e seus respectivos funcionários. Esse é um importante mecanismo utilizado para que as menores organizações possam também oferecer aos seus participantes um plano complementar de aposentadoria, o que seria inviável se elas fossem vistas isoladamente. Hoje, significativa parcela dos fundos de pensão é constituída pelos fundos multipatrocinados, situação regulamentada pela Lei Complementar $\mathrm{n}^{\circ} 109$ de 2001.

O sistema utilizado é o de capitalização, no qual a organização e o funcionário contribuem com percentuais predeterminados para uma conta individual, na qual ocorre a acumulação e investimento desse montante, cujo retorno será, no futuro, a garantia da aposentadoria.

Os Planos podem ser de dois tipos: Benefício Definido (BD) que oferece aos participantes uma aposentadoria cujo valor final é previamente estabelecido e deve ser cumprido independentemente de as principais variáveis, como rentabilidade e tempo de contribuição, ter ocorrido conforme o planejado ou não. Para isso, é necessária a utilização de cálculos atuariais para se chegar ao valor das contribuições.

Como se trata de hipóteses e probabilidades, as organizações patrocinadoras assumem todo o risco em caso de variações não previstas, ou seja, no caso de o retorno do investimento ser abaixo do esperado ou ocorrerem variações nas taxas de juros, nos salários etc., a patrocinadora cobre a diferença até atingir o valor do benefício estabelecido inicialmente.

Os Planos de Contribuição Definida (CD), ao contrário, buscam predeterminar os valores da contribuição dos participantes e da patrocinadora, ou seja, o benefício não seria previamente determinado, mas corresponderia ao valor acumulado durante todo o período de contribuição. Isso significa que os riscos para a organização patrocinadora seriam diminuídos, pois variações na rentabilidade, taxa de juros e outros afetariam diretamente o valor dos benefícios dos aposentados, assumindo estes, assim, os riscos do plano. É claro que, no caso de investimentos bem sucedidos, o acréscimo ao benefício também seria incorporado ao valor pago ao aposentado. Alguns Fundos de Pensão oferecem os dois tipos de plano e deixam a critério do funcionário a opção por aquele ao qual se vinculará.

Como se trata de valores elevados, os investimentos das arrecadações dos fundos são controlados e limitados para a segurança do beneficiário. Esses limites, no Brasil, são ditados pelo Ministério da Previdência e Assistência Social (MPAS) e pelo Conselho Monetário Nacional (CMN) e visam não só diminuir os riscos de investimentos, mas, também, direcionar, de certa forma, a alocação de recursos segundo os interesses do Governo, proporcionando assim, diversificação de investimentos e, conseqüentemente, de riscos e rentabilidade. Os limites máximos exigidos atualmente podem ser observados de forma completa no texto da Resolução CMN n 3.121 de 25/09/2003.

Segundo Fortuna (1997), os investimentos em Renda Fixa (podem atingir até 100\% da carteira) e correspondem aos seguintes tipos: Títulos Públicos Estaduais e Municipais; depósitos a prazo fixo com ou sem emissão de certificado; debêntures não conversíveis, de emissão pública; letras de câmbio de aceite de instituições financeiras; cédulas hipotecárias; notas promissórias comerciais (de emissão pública), letras imobiliárias e hipotecárias, cotas de FIF e FAC voltados para Renda Fixa; depósitos em conta de poupança; ouro físico; entre outros. Os Títulos Públicos representam títulos de responsabilidade do Tesouro Nacional e do Banco Central e créditos securitizados do Tesouro.

Os investimentos em Renda Variável também possuem limites estabelecidos por lei, de acordo com os níveis de risco e a condição das companhias cedentes e dizem respeito a ações de companhias abertas; debêntures conversíveis, de emissão pública; bônus de subscrição de ações de companhias abertas; certificados de depósitos de ações de companhias com sede nos países integrantes do Mercosul; cotas de Fundos de Investimentos em ações autorizados pela CVM (Comissão de Valores Mobiliários); cotas de FIF e FAC voltados para Renda Variável; ações de companhias fechadas adquiridas dentro do Programa Nacional de Desestatização (PND), além de operações com derivativos de renda variável. Os investimentos em ações de uma mesma empresa se limitam a $5 \%$ do total de reservas técnicas, podendo chegar a $10 \%$ no caso de participação maior ou igual a $3 \%$ do IBOVESPA, IBX ou FGV-1005, e não podem representar mais que $20 \%$ do seu capital votante ou total.

Os investimentos no setor imobiliário podem ser em imóveis para uso próprio, imóveis comerciais, investimentos em shopping center, terrenos e outros investimentos autorizados pelo Conselho de Gestão da Previdência Complementar.

Torna-se importante salientar que, em países cujo desenvolvimento dos Fundos de Pensão já atingiu um patamar mais elevado, não existem limites para os investimentos. Estes são regidos pelas leis de mercado e pela necessidade de escolher as aplicações que mais se ajustem à realidade de seus participantes.

Concomitantemente, a nova Legislação da Previdência cria meios para maior segurança dos participantes, através de mecanismos para informar, periodicamente, a situação dos investimentos e o saldo das contas aos participantes.

Além disso, atualmente, vem acontecendo aumento da participação dos funcionários nas decisões sobre o investimento dos fundos, ou seja, eles podem escolher modalidades de carteira, desde as mais seguras até aquelas que teriam, em princípio, um maior risco. Por exemplo, o Fundo de Pensão da Brahma permite que o trabalhador escolha 
o perfil de seus investimentos. Os participantes podem optar por um perfil conservador, no qual $100 \%$ dos investimentos são em renda fixa; moderado, em que até 15\% das aplicações são em renda variável; ou agressivo, cujos investimentos alcançam 25\% para ações (Renda Variável). Em outros países, essa opção é bem difundida, chegando a permitir que os beneficiários opinem até sobre os papéis que comporão a carteira.

A maior parte dos investimentos dos Fundos de Pensão do Brasil vem sendo continuamente aplicada em Fundos de Renda Fixa e Ações (Renda Variável): 46\% e 20\%, respectivamente. A Tabela $3 \mathbf{O}$ denota esse fato, apresentando o volume de recursos e percentual por tipo de aplicação no período de dezembro de 2003 a dezembro de 2005, explicitando quais as preferências das entidades na escolha de sua carteira de aplicação.
Pode-se observar que não há mudanças significativas na composição dos tipos de investimentos, essa composição é praticamente estável nesse período. Note-se que, em cada um dos anos nesse período, os Ativos de Renda Fixa, quando agrupados, atingem aproximadamente $60 \%$ do total de investimentos, enquanto os de Renda Variável (Ações e Fundos de Investimento em Renda Variável) atingem cerca de $30 \%$ do total, percentual esse bem abaixo do limite máximo de 50\%, o que denota certo conservadorismo. Por sua vez, os investimentos em Títulos Públicos (Renda Fixa) também são bem representativos, ultrapassando os R\$27 bilhões em 2003 para próximo de 36 biIhões em 2005, mostrando a importância do setor no que se refere ao financiamento público.

Tabela 3 | Carteira consolidada por tipo de aplicação dos

Fundos de Pensão brasileiros, no período de dez/03 a dez/05

\begin{tabular}{l|c|c|c|c|c|c} 
Discriminação & Dez/03 & \% & Dez/04 & $\%$ & Dez/05 & $\%$ \\
Ações & 40.968 & 18,9 & 51.188 & 20,0 & 59.975 & 20,3 \\
\hline Imóveis & 11.601 & 5,4 & 11.565 & 4,5 & 11.836 & 4,0 \\
\hline Depósitos a prazo & 2.69 & 1,2 & 2.284 & 0,9 & 3.34 & 1,1 \\
\hline Fundos de Investimentos - RF & 96.343 & 44,6 & 119.101 & 46,6 & 137.098 & 46,4 \\
\hline Fundos de Investimentos - RV & 21.536 & 10,0 & 25.908 & 10,1 & 30.772 & 10,4 \\
\hline Empréstimos a participantes & 3.992 & 1,8 & 4.883 & 1,9 & 5.65 & 1,9 \\
\hline Financiamento imobiliário & 3.365 & 1,6 & 3.015 & 1,2 & 2.483 & 0,8 \\
\hline Debêntures & 3.707 & 1,7 & 3.467 & 1,4 & 3.428 & 1,2 \\
\hline Títulos públicos & 27.419 & 12,7 & 29.871 & 11,7 & 35.818 & 12,1 \\
\hline Outros & 4.492 & 2,1 & 4.429 & 1,7 & 4.777 & 1,6 \\
\hline Oper. c/ patrocinadoras & 77 & 0,0 & 78 & 0,0 & 72 & 0,0 \\
\hline Total & 216.19 & & 255.789 & & 295.249 &
\end{tabular}

Fonte: ABRAPP, 2006

\section{REFERENCIAL TEÓRICO}

\subsection{Risco e incerteza sob} o aspecto microeconômico

A Teoria Microeconômica Neoclássica postula o consumidor como um agente maximizador de satisfação, dada sua restrição de renda. Nesse sentido, a função de utilidade é o ponto de partida inicial de toda a análise do comportamento de consumo do indivíduo. Trata-se de um indicador da satisfação do consumidor racional (LEFTWICH, 1994).

Por outro lado, Varian (2003) aborda o tema sob o aspecto da incerteza. Nesse caso, o desejo de consumo não é perene; pelo contrário, muitas vezes ele se torna transitório. Acontece que o indivíduo avalia o consumo em um determinado estado, em que existe um "plano de consumo contingente" (estado 1). Entretanto, em outro momento, o desejo pode simplesmente deixar de existir (estado 2). Assim, a função de utilidade passa a ser o que o autor definiu como "função de utilidade esperada". A utilidade esperada é apresentada conforme a seguinte equação:

$$
u\left(c_{1}, c_{2}, \pi_{1}, \pi_{2}\right)=\pi_{1} v\left(c_{1}\right)+\pi_{2} v\left(c_{2}\right)
$$

em que $u$ é a utilidade esperada; $c_{1}$ e $c_{2}$, os consumos nos estados 1 e $2 ; \pi_{1}$ e $\pi_{2}$, as probabilidades de consumo nos estados 1 e 2 e $v\left(c_{1}\right)$ e $v\left(c_{2}\right)$, as funções de consumo nos estados 1 e 2 , respectivamente.

Por sua vez, Silva (2003) observa que, quando se analisa uma possibilidade de investimento, seja em produção ou formação de portfolio de ativos financeiros juros-rentáveis, não é válida a tomada de decisão em um processo de simples escolha, devido às circunstâncias da incerteza.

Assim, surge o conceito de risco como medida dos possíveis eventos incertos. Ao contrário da incerteza, a medição de risco é objetiva e utiliza ferramentas probabilísticas 
e estatísticas (VARIAN, 2003). Define-se, então, que a avaliação da situação de risco parte da pressuposição de um amplo conhecimento de valores observados flutuando em volta de um valor médio central entre determinados limites calculados (PAULA, 2001).

Dessa forma, o cálculo de riscos é uma maneira objetiva de lidar com incertezas subjetivas ou incertezas decorrentes de eventos desconhecidos, formando, assim, o conceito de expectativas, que influenciam diretamente as decisões de investimento. Nesse caso, a função de utilidade esperada define o grau de aceitação ou aversão ao risco (VARIAN, 2003).

Para Samuelson e Nordhaus (1993), quando ocorre aversão ao risco, a utilidade esperada do indivíduo é côncava em relação à origem e, por outro lado, o indivíduo propenso ao risco tem sua função de utilidade esperada convexa. A Figura 10 retrata essas condições.

Note-se, na Figura 1 (a), que, em condições de incerteza, a utilidade do valor da riqueza no nível $u^{2}$ é maior que a utilidade esperada da riqueza $\left(u^{e}\right)$, isto é, o indivíduo prefere ter o valor da riqueza a arriscar. O contrário pode ser observado na Figura 1 (b), quando $u^{e}>u^{2}$, denotando maior aceitação ao risco.

\subsection{Risco e teoria do portfolio}

Para Assaf Neto (2003), toda vez que a situação de incerteza possa ser quantificada por meio de uma distribuição de probabilidades dos resultados previstos, diz-se que a decisão está sendo tomada sob uma situação de risco. Na visão de Brigham (1999) e Brito (2003), quanto mais estreita a distribuição de probabilidades dos retornos futuros esperados, menor será o risco de um dado investimento.

Segundo Tosta de Sá (1999), risco é um conceito "multidimensional" que cobre quatro grandes grupos: risco de mercado, risco de liquidez, risco operacional e risco de crédito. Desses, o risco de mercado é o que se associa à volatilidade dos preços dos títulos negociados e de cor- relações entre os movimentos desses. Para Duarte Júnior (2001), o risco de mercado depende do comportamento do preço do ativo diante das condições de mercado; para entender e medir possíveis perdas causadas por flutuações do mercado, é importante identificar e quantificar o mais corretamente possível as volatilidades e correlações dos fatores que impactam na dinâmica do preço do ativo.

Gitman (1997) afirma que risco é a possibilidade de obter prejuízo financeiro. No mesmo sentido, Jorion (1998) acrescenta que o risco pode ser definido como a incerteza em relação a resultados, sendo mais bem compreendido em termos de probabilidade. Assim, um modo de medir a escolha sob incerteza é a utilização de distribuições de probabilidades, mais especificamente o modelo de média, variância e desvio-padrão.

Hull (1996) afirma que os riscos de um investimento é o somatório de dois tipos de risco: o sistemático (ou não-diversificável) e o não-sistemático (ou diversificável). Segundo Ross et al. (1998), um risco sistemático é aquele que influencia grande número de ativos, em grau maior ou menor. Um risco não-sistemático é o que afeta um único ativo ou um pequeno número de ativos. Como se trata, então, de um risco específico, ele pode ser minimizado pela diversificação da carteira.

O princípio da diversificação, de acordo com Ross et al. (1998), mostra que a distribuição de aplicações por muitos ativos eliminará parte do risco de investimento, ou seja, aquela parte que se refere ao risco não-sistemático pode ser minimizada com a utilização de ativos que se correlacionam de forma inversa, indicando que a diversificação é, então, importante instrumento para a administração de carteiras de investimento.

A moderna teoria de carteiras foi desenvolvida inicialmente por Markowitz (1952), com a publicação do artigo "Seleção de Carteiras". Para Baima (1998), a grande inovação desse artigo consistiu em relacionar o retorno, dado pelo retorno esperado, e o risco, medido pelo desvio-padrão, de cada carteira de títulos, considerando um infinito

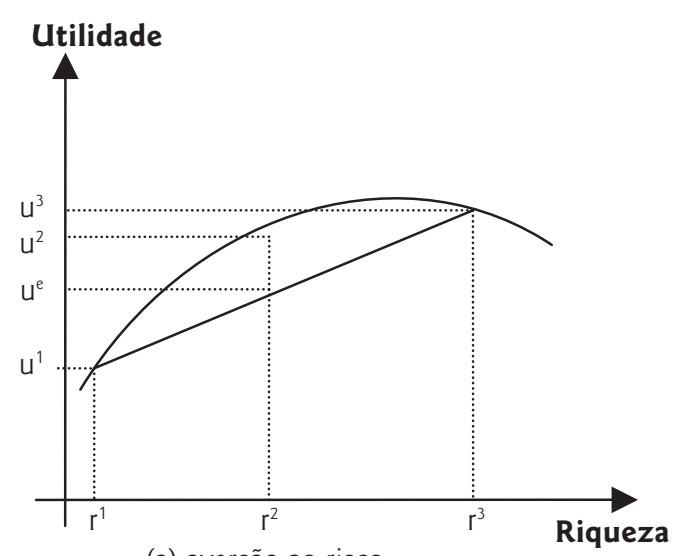

(a) aversão ao risco

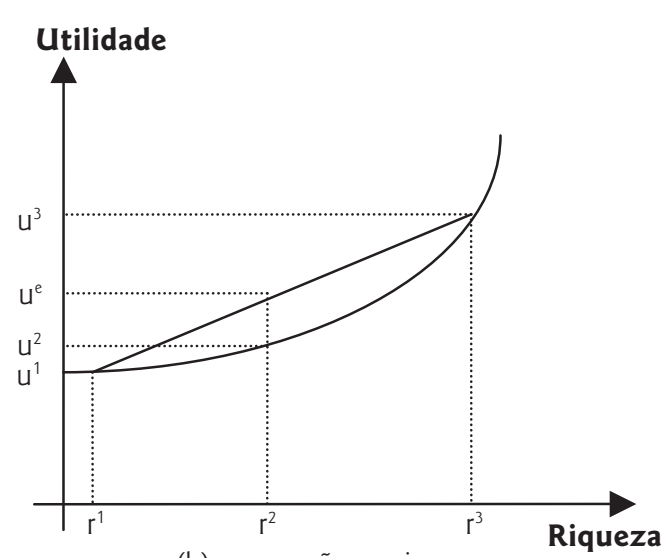

(b) propensão ao risco

Fonte: Adaptado de Varian (2003).

Figura 1 || Função de utilidade esperada, indicando condições de aversão e de propensão ao risco 
número de combinações possíveis que poderiam compor uma carteira e, a partir daí, traçar a curva do conjunto das suas combinações eficientes. Assim, dado um determinado nível de risco, medido pelo desvio-padrão, a carteira mais eficiente para investidores racionais é aquela que oferece maior retorno esperado e vice-versa, ou seja, dado um retorno esperado, a melhor opção seria aquela cujo risco é o mais baixo.

A Teoria do Portfolio trata da seleção de aplicações financeiras capazes de maximizar a utilidade esperada de um investidor através de métodos quantitativos e dados históricos, indicando como construir uma carteira condizente com a combinação risco-retorno apropriada para cada perfil de investidor (MATTOS, 2000).

\subsection{Metodologia para cálculo do risco}

De acordo com Duarte Júnior (2001), diferentes medidas podem ser utilizadas no cálculo do risco de mercado de uma carteira de investimentos, não havendo padronização nesse sentido.

Segundo Gitman (1997), o desvio-padrão, que mede a dispersão em torno de um valor esperado, é o indicador estatístico mais comum de risco. Outras medidas de volatilidade visam, entretanto, capturar características próprias do mercado financeiro, como, por exemplo, a correlação dessa dispersão com os erros passados (GUJARATI, 2000). Para Pereira (2003), em séries de retornos de ativos financeiros é comum o fato de que grandes valores num determinado instante do tempo sejam seguidos por valores também elevados nos períodos subseqüentes, não necessariamente na mesma direção.

Nesse sentido, note-se que o processo de mensuração do risco pode passar pelo estudo de Séries Temporais², tendo em vista que, de acordo com Schwager (1995), as análises das tendências, sazonalidades, ciclos e volatilidades em séries financeiras são de extrema importância dentro de um contexto de incerteza. Para Box e JenkinS (1976), os modelos de análise de séries temporais têm como finalidade o estudo de padrões no comportamento das variáveis, bem como a tentativa de efetuar suas previsões e controle.
Dentro dessa perspectiva das séries temporais, tornase possível modelar autocorrelações entre as séries de retorno de qualquer ativo, visando compreender sua evolução e também buscar expectativas mais reais no que tange à sua previsibilidade. Algumas vezes, entretanto, conforme explica Hamilton (1994), além das informações contidas nas séries, pode ser interessante explicar sua variância. Assim, torna-se praticável também a modelagem dos erros dessa série, ou seja, a volatilidade ou risco. Isso porque, em se tratando de séries temporais de dados financeiros (ações, contratos futuros, moedas, juros etc.), é comum a inconstância da volatilidade, problema típico de dados de corte seccional, mas que é evidente nesse tipo de informação. Afasta-se, assim, do caso clássico dos estudos econométricos de séries temporais em que as variáveis são homoscedásticas, ou seja, têm variância constante e não correlacionadas. Para corrigir esse problema, portanto, podem ser utilizados, entre outros, os Modelos de Volatilidade Condicional. De acordo com Enders (1995), modelos teóricos que utilizam a variância como medida de risco podem ser testados usando a Variância Condicional, através dos modelos da família ARCH/GARCH.

Uma medida de risco de mercado que vem sendo amplamente difundida é a técnica VaR (Value-at-risk), ou Valor em Risco, sendo seu uso defendido por órgãos reguladores e por instituições financeiras (OLIVEIRA, 2002). De acordo com Linsmeier e Pearson (1996), o VaR foi inicialmente usado na década de 80 por empresas financeiras para medir riscos em carteiras de investimentos. Posteriormente, depois de elevados prejuízos nas instituições financeiras e de sérios desastres com derivativos, o Banco J.P. Morgan e Co. tornou sua metodologia para cálculo do risco (VaR) conhecida, difundindo sua utilização (OLIVEIRA, 2002).

Silva Neto (2000) afirma que o VaR é uma técnica que permite calcular a perda máxima de um investimento em um ativo ou em uma carteira de ativos, em determinado período de tempo, dentro de determinado intervalo de confiança. Assim, uma das vantagens dessa medida é sua versatilidade, ou seja, o risco pode ser expresso de várias maneiras diferentes.

\section{MODELO ANALÍTICO}

Para a execução dos objetivos propostos neste artigo, serão compostas carteiras de ativos seguindo o perfil dos investimentos dos Fundos de Pensão brasileiros, bem como os limites legais aos quais essas instituições estão sujeitas. Para efeito de comparação, serão utilizadas carteiras sem e com derivativos agropecuários, além das outras modalidades de investimentos, separadas em três grandes grupos: Renda Fixa, Renda Variável e Imóveis e Financiamentos, de acordo com a própria divisão contida na Resolução CMN 3.121, de setembro de 2003 (ABRAPP, 2004b).

A fim de representar as aplicações em cada um dos grandes segmentos, foram definidos parâmetros comparativos de retorno para cada modalidade, tomando como referência estudos anteriores, como Mattos (2000) e Silva (1998), e instrumentos de benchmark ${ }^{3}$ definidos por alguns Fundos de Pensão brasileiros, como a Caixa de Previdência

\footnotetext{
2 Segundo Gujarati (2000), série temporal é um conjunto de observações dos valores que uma variável assume em diferentes momentos. Para maiores detalhes, ver Wooldridge (2003) e Gujarati (2000).
}

3 Designa um processo contínuo e sistemático para avaliar, medir e comparar produtos, serviços, processos e funções. 
dos Funcionários do Banco do Brasil (PREVI) e o INSTITUTO UFV DE SEGURIDADE SOCIAL - AGROS (2003). Desse modo, tem-se:

- Renda Fixa: Taxa SELIC ${ }^{4}$

- Renda Variável: IBOVESPA Médio ${ }^{5}$

- Imóveis e Financiamentos: INPC 6 + 6\% a.a.

Esse tipo de análise é comum na literatura e se adapta aos objetivos deste trabalho.

Dessa maneira, foram criadas, de acordo com os parâmetros previamente estabelecidos, carteiras com retornos diários entre janeiro de 1999 e maio de 2004, respeitando os feriados e as paralisações das Bolsas de Valores e de Mercadorias. A necessidade de um volume de dados que corroborasse uma análise mais significativa e a estabilidade político-econômica pela qual o país passou durante esses anos justificam o período considerado na análise.

Com intuito de capturar de forma eficiente os efeitos da introdução de derivativos agropecuários nas carteiras das citadas instituições, estabeleceu-se como distribuição básica dos investimentos a média das aplicações dos Fundos de Pensão brasileiros, de acordo com a ABRAPP (2004a), como se pode observar na Tabela $4 \mathbf{0}$.

Com relação aos derivativos agropecuários, foram utilizados os cinco contratos com maior volume de negociações na Bolsa de Mercadorias \& Futuros (BMEF), entre os anos de 1999 e 2004: café arábica, boi gordo, álcool, milho e açúcar. Foi criada, desse modo, uma carteira de derivativos ponderada pelo volume de negociações dos produtos citados. Os retornos de cada derivativo foram obtidos através de seus respectivos ajustes diários, conforme Mol (2003), organizados de acordo com o primeiro vencimento ${ }^{7}$.

Essa carteira formada por contratos futuros foi introduzida nas carteiras sem contratos, para que se verificasse seu efeito. Como não faz parte do escopo do artigo encontrar a carteira eficiente, na qual se indicaria a quantidade ótima de contratos futuros a ser utilizada, buscou-se estabelecer um volume fixo da introdução desse tipo de ativo, no caso, o montante representativo de $1 \%$ de todos os investimentos de cada Fundo de Pensão. Esse valor se aplica dentro dos limites legais sob os quais essas instituições estão sujeitas e demonstra um caráter mais conservador, postura recorrente e aceitável nas instituições de previdência complementar no Brasil.

Para obtenção do risco de investimento a ser analisado, utilizou-se a metodologia Valor em Risco (VaR). Pode-se obter o VaR para determinado intervalo de confiança através de sua Função de Distribuição de Probabilidade, chegando ao valor máximo do risco (ou volatilidade) para dado nível de significância. Neste trabalho, depois de ajustada a função de densidade, utilizou-se o intervalo de confiança de $95 \%$. Assim, tem-se o cálculo do VaR de acordo com a equação (1).

$$
\operatorname{Pr}\{\Delta \Pi t \leq \operatorname{VaR} t\}=95 \%
$$

em que $\Delta \Pi$ t é volatilidade da carteira $t ; 95 \%$, nível de confiança e VaRt, valor da perda máxima da carteira de acordo com a Função de Distribuição Acumulada.

A volatilidade do portfolio a ser utilizada no cálculo do VaR, por sua vez, será modelada utilizando-se a metodologia de séries de tempo, mais especificamente os modelos auto-regressivos heteroscedásticos (família ARCH/GAR$\mathrm{CH})^{8}$. Esses são calculados após terem sido estimados os retornos das séries através de modelos regressivos convencionais, conhecidos como Auto-Regressivos com Média Móvel (ARMA). De posse desse cálculo e verificando problemas de heteroscedasticidade nos erros originários da estimação (Teste Multiplicador de Lagrange ${ }^{9}$ ), esses são modelados até atingirem o melhor ajuste. No caso de uma estimação da volatilidade condicional pelo processo Garch $(1,1)$, conforme indica Silva (2002) e Hamilton (1994), procede-se de acordo com a seguinte equação:

$$
\sigma_{t}^{2}=\alpha_{0}+\alpha_{1} \varepsilon_{t-1}^{2}+\beta_{1} \sigma_{t-1}^{2}
$$

em que $\sigma^{2}$ é variância condicional ou volatilidade; $\alpha_{0}, \alpha_{1}$, $\beta_{1}$, parâmetros do modelo econométrico; $\varepsilon^{2}$, quadrado dos resíduos ou choque acerca da volatilidade e t, período.

Tabela 4 | Carteira Média dos Fundos de Pensão brasileiros por modalidade de investimento em 2004

\begin{tabular}{l|c} 
Modalidade de aplicação & Perfil Médio(\%) \\
\hline Renda fixa & 55,20 \\
\hline Renda variável & 31,18 \\
\hline Imóveis e financiamentos & 13,67 \\
\hline Total & 100,00
\end{tabular}

Fonte: Dados da pesquisa

\footnotetext{
4 A taxa SELIC (Sistema Especial de Liquidação e Custódia) é a taxa de juros básica da economia definida pelo Banco Central do Brasil, ou seja, as taxas de mercado são balizadas pela SELIC.

5 O índice BOVESPA representa comportamento médio das ações mais negociadas na Bolsa de Valores de São Paulo (BOVESPA).

6 O Índice Nacional de Preços ao Consumidor (INPC) é uma das mais utilizadas medidas de inflação do país. Ele mede mensalmente a variação dos preços de uma determinada cesta de produtos.

7 Considerando que para cada dia existem contratos abertos com vários vencimentos, criou-se o padrão através do Primeiro Vencimento, ou seja, levaram-se em conta os contratos com os vencimentos mais próximos, passando para o posterior logo após seu fechamento.

8 Para maiores detalhes sobre os modelos ARCH/GARCH, ver Hamilton (1994) e Enders (1995).

9 O Teste do Multiplicador de Lagrange, proposto por Engle (1982) e presente em grande parte dos softwares econométricos, visa detectar a presença de heteroscedasticidade nos erros do modelo estimado.
} 


\subsection{Fonte de dados}

Foram utilizados dados referentes aos valores dos ajustes diários dos contratos futuros das commodities agropecuárias café arábica, boi gordo, álcool, açúcar e milho negociadas na BMEF, bem como valores diários do Índice BOVESPA Médio e dos parâmetros comparativos citados anteriormente: taxa SELIC ao dia e INPC, entre os dias 4 de janeiro de 1999 e 31 de maio de 2004, respeitando os feriados e paralisações da BMEF e da BOVESPA, totalizando 1.358 observações.

\section{RESULTADOS}

O primeiro passo para a consecução dos resultados propostos nesta pesquisa consistiu em realizar o estudo das correlações entre as carteiras sem contratos futuros agropecuários e a carteira formada com os próprios derivativos, tanto para contratos de compra como para os de venda.

Procedendo desse modo, obtiveram-se as correlações entre as carteiras formadas sem contratos futuros agropecuários e a carteira formada com os contratos, tanto para compra como para venda, conforme indica a Tabela $5 \mathbf{0}$.

A teoria de Markowitz indica que os maiores benefícios gerados pela diversificação de uma carteira advêm de ativos com correlações altas e negativas, ou seja, mais próximas da unidade negativa (-1). Foi escolhida, dessa forma, a carteira de futuros para venda; mesmo não possuindo essa uma correlação elevada na série considerada, seu valor negativo sugere uma melhor aptidão para diversificação que os contratos de compra. Essa análise torna-se ferramenta importante para os Fundos de Pensão no que se refere à escolha dos ativos mais apropriados para o processo de diversificação, poupando tempo e atingindo resultados mais significativos.

Assim, essa carteira de venda de contratos futuros agropecuários foi inserida nos perfis sem futuros agropecuários com a ponderação de $1 \%$ em relação ao total de investimentos.

Como se trata de uma análise econométrica de séries temporais, um aspecto comum que pode gerar problemas na avaliação dos modelos estimados é a não-estacionariedade das séries. Diante disso, foram realizados os testes de estacionariedade (testes de Dickey \& Fuller Aumentado e Phillips $E$ Perron ${ }^{10}$ ) em cada uma das séries de retorno das carteiras sem e com contratos futuros, indicando a ausên- cia do problema, ou seja, todas as séries são estacionárias ao longo do tempo ${ }^{11}$.

Analisando-se as estatísticas básicas das séries, conforme a Tabela $6 \bullet$, nota-se maior concentração dos valores dos retornos em torno da média das carteiras com contratos futuros. Além disso, o formato das curvas indica as já citadas características das séries financeiras, entre elas a assimetria e curtose ${ }^{12}$, afastando a possibilidade de se tratar de uma série que segue a distribuição normal. Observe-se que, para as duas carteiras, foi rejeitada a hipótese de normalidade através do teste de Jarque-Bera.

Com essas considerações, note-se que as características próprias das séries financeiras (assimetria, curtose e autocorrelação entre os erros) discutidas anteriormente são refletidas claramente nas séries que constituem este estudo. Diante disso, buscou-se modelar os retornos das séries, a fim de entender o comportamento destes. Utilizou-se para esse fim, como é próprio dos estudos de séries temporais (em que se espera uma dependência entre os valores ao longo do tempo), um processo auto-regressivo e de média móvel (ARMA).

Logo a primeira modelagem - no caso, um ARMA $(1,1)$ - se mostrou bem significativa, indicando forte correlação entre os retornos por meio da análise de um período (lag). Procedeu-se, dessa forma, à análise para verificação de problemas de heteroscedasticidade nos erros do modelo, que, se confirmada, indicaria necessidade de correção.

A partir do teste do Multiplicador de Lagrange, comprovou-se, então, que os resíduos dos modelos, ou seja, a volatilidade de cada carteira, não eram constantes ao longo do tempo e, ainda, se correlacionavam com seus valores passados. Para correção do problema de heteroscedasticidade, procedeu-se à modelagem dos erros a par-

Tabela 5 - Correlações entre os retornos das carteiras formadas pela média dos investimentos dos Fundos de Pensão e os retornos das carteiras formadas com os contratos futuros para compra e venda entre 1999 e 2004

\begin{tabular}{c|c} 
Tipo de contrato & Perfil Médio sem futuros \\
\hline Carteira de Futuros - venda & $-0,0793$ \\
\hline Carteira de Futuros - compra & 0,0793
\end{tabular}

Fonte: Dados da pesquisa

10 Para maiores informações, consultar Gujaratl (2000) e Phillips e Perron (1988).

11 A tabela com os resultados completos desse teste encontram-se no Apêndice B.

12 Para maiores detalhes, ver Wooldridge (2003) e Gujarati (2000). 
Tabela 6 Estatísticas básicas das séries de retorno das carteiras do Perfil Médio

\begin{tabular}{l|c|c} 
& Sem contratos futuros & Com 1\% da carteira em contratos futuros \\
Média & 0,0717 & 0,0712 \\
\hline Mediana & 0,0917 & 0,0935 \\
\hline Máximo & 4,5131 & 4,5013 \\
\hline Mínimo & $-2,7219$ & $-2,6836$ \\
\hline Desvio-padrão & 0,5965 & 0,5894 \\
\hline Assimetria & 0,2751 & 0,2889 \\
\hline Curtose & 7,6836 & 7,8345 \\
\hline Teste de normalidade & & 1341,38 \\
\hline Estatística Jarque-Bera & 1258,34 & 0,0000 \\
\hline Probabilidade JB & 0,0000 & 1358
\end{tabular}

Fonte: Resultados da pesquisa

tir de modelos de volatilidade condicional, até encontrar o melhor processo em termos de significância. Para efeito de estimação desse tipo de processo, utiliza-se em geral o Método de Quase-Máxima Verossimilhança, tendo em vista que os erros são distribuídos normalmente. Além do nível de significância indicado pelo p-valor de cada variável, considerou-se, também, para a obtenção do modelo que tornava os resíduos mais robustos à heteroscedasticidade, a análise das seguintes estatísticas: Critério de Informação de Schwarz (SIC), Critério de Informação de Akaic (AIC) e Soma dos Quadrados dos Resíduos (SQR) ${ }^{13}$. Quanto menores os seus valores, melhor estimado estaria o modelo.
Torna-se importante observar que, à medida que os resíduos são modelados, a estimação anterior dos retornos pode se tornar não-significativa, sendo necessário um processo contínuo de adaptação até encontrar os meIhores coeficientes em termos de significância. A necessidade de comparação entre as carteiras de investimento mostrou ser importante a busca de um ajustamento comum entre elas, desde que não prejudicasse o processo de modelagem.

As Tabelas 70 e 80 indicam os resultados dos coeficientes e principais estatísticas da modelagem dos retornos e da variância das carteiras referentes ao Perfil Médio.

Tabela 7 Resultados do modelo estimado da carteira teórica sem contratos futuros

\begin{tabular}{|c|c|c|c|c|}
\hline & Coeficiente & Erro-padrão & Estatística z & p-valor (z) \\
\hline \multicolumn{5}{|c|}{ ARMA $(1,2)$} \\
\hline C & 0,0654 & 0,0169 & 3,8600 & 0,0001 \\
\hline$A R(1)$ & $-0,9583$ & 0,0156 & $-61,4866$ & 0,0000 \\
\hline $\mathrm{MA}(1)$ & 1,1740 & 0,0315 & 37,2213 & 0,0000 \\
\hline \multirow[t]{2}{*}{$\mathrm{MA}(2)$} & 0,1881 & 0,0291 & 6,4604 & 0,0000 \\
\hline & \multicolumn{3}{|c|}{$\begin{array}{l}\text { Variância condicional } \\
\operatorname{EGARCH}(1,1)\end{array}$} & \\
\hline C & $-0,1333$ & 0,0390 & $-3,4176$ & 0,0006 \\
\hline$\left|\frac{\varepsilon_{t-1}}{\sigma_{t-1}}\right|$ & 0,1045 & 0,0321 & 3,2518 & 0,0011 \\
\hline$\frac{\varepsilon_{t-1}}{\sigma_{t-1}}$ & $-0,0600$ & 0,0216 & $-2,7704$ & 0,0056 \\
\hline $\ln \left(\sigma_{t-1}^{2}\right)$ & 0,9585 & 0,0154 & 62,0902 & 0,0000 \\
\hline \multirow[t]{2}{*}{ Estatísticas } & SQR & 452,0011 & $\mathrm{SIC}$ & 1,6426 \\
\hline & AIC & 1,6119 & $\begin{array}{c}\text { Prob } \\
\text { (F-statistic) }\end{array}$ & 0,0000 \\
\hline
\end{tabular}

Fonte: Resultados da pesquisa 
Tabela 8 Resultados do modelo estimado da carteira teórica com 1\% de contratos futuros

\begin{tabular}{|c|c|c|c|c|}
\hline & Coeficiente & Erro-padrão & Estatística z & p-valor (z) \\
\hline \multicolumn{5}{|c|}{ ARMA $(1,2)$} \\
\hline $\mathrm{C}$ & 0,0617 & 0,0166 & 3,7105 & 0,0002 \\
\hline$A R(1)$ & $-0,9772$ & 0,0086 & $-114,1920$ & 0,0000 \\
\hline $\mathrm{MA}(1)$ & 1,1771 & 0,0295 & 39,9410 & 0,0000 \\
\hline \multirow[t]{2}{*}{$\mathrm{MA}(2)$} & 0,1818 & 0,0290 & 6,2773 & 0,0000 \\
\hline & \multicolumn{3}{|c|}{$\begin{array}{l}\text { Variância condicional } \\
\operatorname{EGARCH}(1,1)\end{array}$} & \\
\hline C & $-0,1799$ & 0,0621 & $-2,8982$ & 0,0038 \\
\hline$\left|\frac{\varepsilon_{t-1}}{\sigma_{t-1}}\right|$ & 0,1187 & 0,0405 & 2,9334 & 0,0034 \\
\hline$\frac{\varepsilon_{t-1}}{\sigma_{t-1}}$ & $-0,0656$ & 0,0245 & $-2,6810$ & 0,0073 \\
\hline $\ln \left(\sigma_{t-1}^{2}\right)$ & 0,9327 & 0,0285 & 32,7554 & 0,0000 \\
\hline \multirow[t]{2}{*}{ Estatísticas } & SQR & 443,4678 & $\mathrm{SIC}$ & 1,6228 \\
\hline & AIC & 1,5921 & $\begin{array}{c}\text { Prob } \\
\text { (F-statistic) }\end{array}$ & 0,0000 \\
\hline
\end{tabular}

Fonte: Resultados da pesquisa

Sendo possível atingir o ajustamento comum dentro de elevados parâmetros de significância, tem-se que as carteiras analisadas foram modeladas através de um processo ARMA $(1,2)$ completo com constante ${ }^{14}$, para os retornos, $e$ um EGARCH $(1,1)$, para a volatilidade condicional.

$\mathrm{O}$ coeficiente relacionado ao termo $\ln \left(\sigma_{t-1}^{2}\right)$ indica a persistência dos choques nos resíduos dos retornos das carteiras. Observe-se que, para as referidas carteiras, foram verificadas elevadas persistências (coeficiente próximo da unidade), denotando que, nessas séries, as novas informações levam um tempo considerável para serem absorvidas pelos agentes.

Com relação à assimetria da volatilidade entre os choques altistas ou baixistas, notou-se, através dos coeficientes do parâmetro $\frac{\varepsilon_{t-1}}{\sigma_{t-1}}$, que, em todas as séries do Perfil Médio, era caracterizada a assimetria. Desse modo, pela análise da significância dos coeficientes desse parâmetro (todos foram significativos a 99\% de confiabilidade), aceita-se a hipótese de que são diferentes de zero. Embora sem valores expressivos nas duas séries, o fato de serem significativos indica que choques de alta ou baixa terão efeitos diferentes na volatilidade das séries. Como os coeficientes estimados se mostraram menores que zero $(\gamma<0)$, conclui-se que os choques positivos geram menor volatilidade que os choques negativos da mesma magnitude.

Esses modelos deram origem às estimativas da volatilidade $\left(\sigma^{2}\right)$ para cada dia, ou seja, a volatilidade para ser utilizada no cálculo do Value-at-risk foi extraída a partir do erro estimado dentro do modelo ajustado para cada carteira, gerando, para cada uma delas, uma distribuição de volatilidades diárias. A partir dessa distribuição, tornouse possível o cálculo do valor crítico, conforme indica a equação (1), que é o valor da perda máxima esperada para um dia.

Nota-se, de forma geral que as distribuições das volatilidades não têm características de uma distribuição normal, sendo claramente assimétricas e possuindo caudas gordas (leptocúrticas ou com elevada curtose).

Na Tabela $9 \bullet$, pode-se observar a mudança nas estatísticas básicas da volatilidade estimada, indicando a diminuição dos valores máximos, mínimos e da média, comprovando a redução do risco.

A partir do exposto, faz-se necessário, finalmente, calcular o Value-at-Risk (VaR) para consecução dos objetivos finais do estudo. A partir das distribuições das volatilidades, o VaR para o valor crítico de $95 \%$ pôde ser encontrado por meio do cálculo do percentil referente aos $95 \%$ de confiabilidade.

O cálculo do percentil pode ser feito para quaisquer valores críticos. No presente trabalho foi utilizado o percentil de $95 \%$, ou seja, colocando a distribuição em ordem crescente, encontra-se o valor do qual apenas $5 \%$ das observações estão acima ou, alternativamente, que 95\% dos valores da série estão abaixo.

Dessa forma, para esse nível de confiabilidade, encontrou-se a perda máxima esperada ou, em outras palavras, a volatilidade máxima estimada ( $\sigma^{2}$ máxima) para esse nível de significância. Para se chegar ao VaR, obteve-se a Raiz 
Tabela 9 Estatísticas básicas das séries de volatilidades diárias para as carteiras teóricas referentes ao Perfil Médio

\begin{tabular}{l|c|c}
\hline $\begin{array}{l}\text { Composição das carteiras em relação } \\
\text { aos contratos futuros (CF) }\end{array}$ & Sem CF & Com 1\% \\
\hline Máximo & 1,9418 & 1,9841 \\
\hline Mínimo & 0,1335 & 0,1464 \\
\hline Média & 0,3150 & 0,2974
\end{tabular}

Fonte: Resultados da pesquisa

Quadrada do valor encontrado devido à necessidade de transformação para termos percentuais. O VaR é representado, então, por $\sigma$ para cada carteira. De forma similar, pode-se calcular o VaR em termos financeiros, ou seja, considerando a média dos investimentos dos Fundos de Pensão nos últimos anos (R\$167.056,00 milhões $^{15}$ ), temse uma ponderação do montante investido, ou seja, do valor sujeito ao risco de mercado.

A Tabela $10 \boldsymbol{D}$ indica os resultados finais da pesquisa para a média dos investimentos dos fundos de pensão brasileiros, utilizando o percentil de $95 \%$.

Note-se que o VaR passou de $0,72 \%$ na carteira sem contratos futuros agropecuários para 0,69\% na carteira que continha derivativos. Parece uma variação não tão elevada, mas, quando se considera o montante de investimentos desses fundos no Brasil, a diferença torna-se importante. Desse modo, a carteira sem futuros teria uma perda máxima esperada ao dia de $\mathrm{R} \$ 1.204,15$ milhões, enquanto a carteira com $1 \%$ de derivativos teria um $\mathrm{VaR}$ de $\mathrm{R} \$ 1.160,04$ milhões, uma diferença que gira em torno dos R\$ 44 milhões por dia, ou seja 3,66\% a menos de risco.

Quando comparado com a queda no retorno médio diário, 1,39\%, nota-se que o risco cai mais do que proporcionalmente ao retorno, indicando que o processo de diversificação foi satisfatório.

Tabela 10 | Resultados finais para cálculo do VaR diário para as carteiras através do percentil de 95\%

\begin{tabular}{l|c|c} 
Composição das carteiras & Sem CF & Com 1\% \\
Percentil (95\%) & 0,520 & 0,482 \\
\hline $\operatorname{VaR}(\%)$ & 0,721 & 0,694 \\
\hline VaR (R\$ milhões) & $\mathrm{R} \$ 1.204,15$ & $\mathrm{R} \$ 1.160,04$ \\
\hline Retorno médio diário (\%) & 0,072 & 0,071
\end{tabular}

Fonte: Resultados da pesquisa

\section{CONSIDERAÇÕES FINAIS}

Os resultados obtidos com a aplicação da modelagem estatística e do cálculo do risco e retorno esperados a partir dos parâmetros preestabelecidos indicaram um desempenho satisfatório das carteiras teóricas dos Fundos de Pensão a partir da introdução, nestas, de contratos futuros agropecuários.

O trabalho torna-se mais significativo à medida que se analisam os montantes financeiros envolvidos. Considerando-se, por exemplo, que os Fundos de Pensão invistam, de forma geral, $1 \%$ de seus ativos em derivativos, seriam injetados no mercado futuro de commodities agropecuárias mais de $R \$ 2$ bilhões, valor que representa, dentro da movimentação financeira de 2004 , aproximadamente $10 \%$ de todos os recursos investidos. Desse modo, uma maior participação das Entidades Fechadas de Previdência Complementar, nesse mercado, geraria benefícios notórios para a sua liquidez.

Os Fundos de Pensão podem, por fim, a partir deste estudo preliminar, buscar técnicas e instrumentos financeiros que promovam ainda mais seu desenvolvimento e propiciem uma elevação de sua importância, tanto para a economia do país como para os aposentados e beneficiários que anseiam pelos recursos oferecidos pelos planos de previdência complementar. Essa importância passa, necessariamente, por uma gestão de investimentos de qualidade. 


\section{Referências}

ASSAF NETO, A. Mercado financeiro. 5.ed. São Paulo: Atlas, 2003.

ASSOCIAÇÃO BRASILEIRA DAS ENTIDADES FECHADAS DE PREVIDÊNCIA PRIVADA - ABRAPP. Estatísticas. São Paulo, 2004a. Disponível em: <http://www.abrapp.org.br/estatisticas/consolidado/2004/ cons295\%jan04.pdf >. Acesso em: 20 mar. 2004.

ASSOCIAÇÃO BRASILEIRA DÁS ENTIDADES FECHADAS DE PREVIDÊNCIA PRIVADA - ABRAPP. Estatísticas. São Paulo, 2004b. Disponível em: <http://www.abrapp.org.br/estatisticas/Limites\%AD_aplica\%E 7\%E3o_diversifica\%E7\%E3o_EFPC_Res_CMN3121.xls>. Acesso em: 20 mar. 2004.

ASSOCIAC̄̃̃O BRASILEIRA DAS ENTIDADES FECHADAS DE PREVIDÊNCIA PRIVADA - ABRAPP. Estatísticas. São Paulo, 2006c. Disponível em: <htttp://www.abrapp.org.br/estatisticas/consolidado/2006.pdf >. Acesso em: 25 abr. 2006.

BAIMA, F. R. Avaliação de desempenho dos investimentos dos fundos de pensão no Brasil. Dissertação (Mestrado em Economia da Produção) - Universidade Federal de Santa Catarina,1998.

BOX, G. E. P.; JENKINS, G. M. Time series analysis: forecasting and control. 1976.

BRIGHAM, E. F. Fundamentos da moderna administração financeira. Rio de Janeiro: Campus, 1999.

BRITO; O. Controladoria de risco-retorno em instituições financeiras. São Paulo: Saraiva, 2003.

DUARTE JÚNIOR, A. M. Risco: definições, tipos, medição e recomendações para o seu gerenciamento. In: LEMGRUBER, E. F. et al. (org.) Gestão de risco e derivativos: aplicaçốes no Brasil. São Paulo: Atlas, 2001.

ENDERS; W. Applied Econometric Time Series. John Wiley \& Sons; Inc., 1995

FONTES, R. E.; CASTRO JÚNIOR, L. G. et al. Investimentos em commodities agropecuárias - uma análise comparativa do risco e retorno entre o mercado derivativo e o acionário. In: CONGRESSO BRASILEIRO DE ECONOMIA E SOCIOLOGIA RURAL, 42, Cuiabá. Anais... Brasília: SOBER, 2004.

FORTUNA, E. Mercado financeiro: produtos e serviços. São Paulo: Qualitymark; 1997.

GITMAN, L. J. Princípios de administração financeira. São Paulo: Harbra, 1997.

GUJARATI, D. N. Econometria básica. São Paulo: Makron Books, 2000.

HAMILTON, J. D. Time Series Analysis. New Jersey: Princeton University Press, 1994

HULL, J. Introdução aos mercados futuros e de opções. 2,ed. rev. e ampl. São Paulo: BM\&F/Cultura Editores Associados, 1996.

INSTITUTO UFV DE SEGURIDADE SOCIAL - AGROS. Política de investimentos. Viçosa, 2003. Disponível em: <http://www.agros.org.br/ política deinvestimento $>$. Acesso em: 06 jan. 2003.

JORION, P. Value at risk - a nova fonte de referência para o controle do risco de mercado. São Paulo: BM\&F, 1998.

LEFTWICH, R, H. O sistema de preços e a alocação de recursos. 8.ed. São Paulo: Pioneira, 1994.

LINSMEIER, T. J.; PEARSON, N. D. Risk measuring: an introduction to value at risk. Office for Futures and Options Research Working Paper, 44. p., Apr. 1996.

MARKOWITZ, H. M. Portfolio selection. The Journal of Finance, v. 7, n. 1, p. 77-91, Mar. 1952

MATTOS, F. L. Utilização de contratos futuros agropecuários em carteiras de investimento: um estudo de viabilidade. Dissertação (Mestrado em Economia Aplicada) - Escola Superior de Agricultura Luiz de Queiroz, Piracicaba, SP, 2000.

MOL, A. L. R. Value at risk como medida de risco da volatilidade dos ajustes diários em mercados futuros de café. Dissertação (Mestrado em Administração) - Universidade Federal de Lavras, Lavras, MG, 2003.

OLIVEIRA, M. E. D. Análise do risco de carteiras de ações de Fundos de Pensão com a técnica VaR (valor em risco): o caso AGROS. Monografia (Graduação em Economia) - Universidade Federal de Viçosa, Viçosa, MG, 2002.

PAULA, R. F. Gerenciamento de risco de taxa de juro em Fundos de Pensão - redesenhando a estratégia de imunização com o uso de derivativos. Revista Resenha BM\&F, São Paulo, n. 146, 2001.

PEREIRA, P. L. V. Estimação de volatilidades. São Paulo: RiskTech.com - O Portal Brasileiro de Risco, 2003. Disponível em: <http://www. risktech.com.br/>. Acesso em: 10 out: 2003.

PEREIRA FILHO, J. R. O uso de derivativos para proteção de carteiras de ações: a experiência da Eletros. Revista Resenha BM\&F, São Paulo, n. $148,2002$.

ROSS, S, A.; WESTERFIELD, R. W.; JORDAN, B. D. Princípịos de administração financeira. São Paulo: Atlas, 1998.

SAMUELSON, P.; NORDHAUS, W. Economia. 14.ed. Lisboa: McGraw-Hill, 1993.

SCHWAGER, J. D. Fundamental analysis. New York: Jonh Wiley \& Sons, 1995.

SILVA, N. S. Usando commodities para diminuir o risco-retorno de um portfólio indexado. Revista Resenha BMß $F$, Sã̀o Paulo, n. 112, fev./mar. 1998.

SILVA, J. C. Estimação do valor em risco usando informação intra diária. Dissertação (Mestrado em Economia) - Fundação Getúlio Vargas, Rio de Janeiro, RJ, 2002.

SILVA, J. M. A. Fundamentos de teoria macroeconômica. Viçosa: UFV, 2003 
SILVA NETO, L. A. Derivativos: definições, emprego e risco. 3.ed. São Paulo: Atlas, 2000.

TOSTA DE SÁ, G. Administração de investimentos: teoria de carteiras e gerenciamento do risco. Rio de Janeiro: Qualitymark, 1999. 376 p. VARIAN, H. R. Microeconomia: princípios básicos. Rio de Janeiro: Campus, 2003.

WOOLDRIDGE, J. F. Introductory econometrics: a modern approach. 2.ed. Thomson, 2003.

\section{NOTA - Endereço dos autores}

Universidade Federal de Viçosa

Departamento de Administração

Campus UFV, S/no,

Viçosa - MG

36571-000
Universidade Estadual do Oeste do Paraná

Campus de Toledo - Colegiado de Economia

R. Pinheiro Machado, 1323 - Jd Gisella

Toledo - PR

85905-300 